\title{
O RISO COMO LEMBRANÇA
}

Ao professor Teiiti Suzuki, in memoriam

Aurora F. Bernardini

RESUMO: O presente artigo foi escrito como uma homenagem ao Professor Teiiti Suzuki. Para tanto são retomados alguns fios das conversações mantidas entre ele $\mathrm{e}$ a autora, particularmente os que dizem respeito às teorias bergsonianas do riso, uma vez que foi Bergson um dos filósofos favoritos do Professor Suzuki. Ao mesmo tempo em que é sintetizado o livro Le Rire, procurando reproduzir seus aspectos ainda atuais e sempre mantendo-se o mais possível rente ao texto, são introduzidas consideraçōes de críticos mais recentes, particularmente em relação à paródia e à ironia, respectivamente de Iuri Tinianov e de Paul de Man.

ABSTRACT: This article was written in honour of the memory of Professor Teiiti Suzuki. It begins by recalling conversations between Professor Suzuki and the author, particularly those concerning Bergson's theories of the comic. then, after summarizing Le Rire, with emphasis on its contemporaneity, other more recents critics of parody and irony are considered: Jurij Tynianov and Paul de Man, respectively.

PALAVRAS-CHAVE: Teiiti Suzuki, Bergson, Cômico, Paródia, Ironia

KEYWORDS: Teiiti Suzuki, Bergson's Le Rire, Tynianov's “Theory of Parody”, de Man's theory of irony.

Dizia um ditado russo, da época da antiga União Soviética, que o que resta da gente, quando a gente se vai, são partes de nós mesmos na memória de quem nos quis bem. Se assim for, e muito bem eu quis ao amigo e colega Teiiti Suzuki, restou-me dele, juntamente com um quadro admirável, "As Piranhas do Rio São Francisco", que ele me deu após uma esplêndida aula de pintura na praia de Guaiuba, a lembrança de uma grande alegria. Não se trata de alguma alegria em particular, embora tenham sido muitos 
os momentos alegres, jocosos, cômicos ou mesmo irônicos que atravessamos juntos, no quarto de século em que nos cruzamos nas cercanias do antigo Curso de Línguas Orientais. Trata-se mais de um adensamento que o envolvia - e aqui uso uma imagem de Henri Bergson, que com Platão e Aristóteles formava a tríade de seus filósofos favoritos - ao qual eu era particularmente sensível.

Um tipo de hụmor muito versátil, que se manifestava em tiradas breves, naturalmente imprevistas. Lembro-me da comemoração dos seus setenta anos, quando, sentada ao lado dele, falávamos de $O$ Crisântemo e a Espada, de Ruth Benedict. - Então, professor, agora é que o senhor vai ter a vida que pediu a Deus!' - E ele, sacudindo a cabeça, com ar resignado: - É que não dá para fazer mais nada.

Outra vez, já aposentado, foi convocado com urgência para votar em não sei mais qual eleição de nosso conturbado Departamento, em que a parte "progressista" perigava, como sempre, de ser tragada pela "reacionária". Atendeu ao chamado com tảmanha presteza, que, ao atravessar a avenida em frente à Casa do Japão, foi atropelado. Contava isso logo em seguida, ainda mancando pelo baque, com total tranqüilidade, e todas nós, consternadas, perguntávamos se não era o caso de acompanhá-lo a um pronto-socorro. - Absolutamente, - dizia ele sorrindo - para que tenho um filho em casa que é ortopedista?

Isso, sem contar as vezes em que, finda a aula de cultura japonesa que ministrava na Casa do Japão, nos encontrávamos no "refeitório" para saborear, entre uma pilhéria e outra, uma das pingas especiais que alguém, sabedor de seu conhecimento enciclopédico a respeito, lhe trazia de presente do Norte ou do Sul. Ou quando, no avião rumo a Cuba por conta do congresso da Associação Latino-Americana de Estudos Afro-Asiáticos, de cuja seção brasileira foi presidente durante algum tempo, foi encontrado dormindo com $A$ Poética de Aristóteles em grego em cima dos olhos. Enfim.

Quando, ainda nos anos 70 resolvi ministrar um curso de pós-graduação sobre Pirandello, junto à área de Teoria Literária e Literatura Comparada da USP, tive ocasião de falar com o professor Suzuki, sobre o que ele achava do humorismo, visto Pirandello ter escrito um livro com esse título, e visto ter eu na época acabado de traduzir, com Homero Freitas de Andrade, sua peça Henrique IV, que sob este aspecto, me intrigava muito. Foi nessa ocasião que ele me falou de Le Rire de Bergson. A partir de então tive ocasião de dedicar-me ao estudo do riso em uma série de pesquisas, de Bergson a Paul de Man, passando por Pirandello, Tinianov e outros especialistas.

São as considerações provindas dessas leituras que gostaria de discutir, agora, com Teiiti Suzuki. Não podendo fazê-lo pessoalmente, faço-o em intenção. Tenho presente que a emoção da sua lembrança, há tempo espalhada sobre os diferentes objetos que constituíram sua vida, está sobre nós também - como quer seu filósofo predileto no livro Matière et Mémoire, que acompanhou Suzuki no túmulo - numa rede incessante de intuições criativas.

Le Rire, ou seja, no caso, o riso especialmente provocado pelo cômico foi publicado por Henri Bergson na Revue de Paris em 1899, como um longo ensaio composto pela reunião de três artigos.

1. Ruth Benedict, no livro citado, refere-se ao fato de que, na tradição japonesa, à criança até os sete anos e ao homem, após os setenta, é concedida uma liberdade toda particular. 
No primeiro, que define o "processo de fabricação" do cômico em geral e sua força de expansão, é focalizado, com exemplos retirados do folklore e da literatura, o cômico das formas e o cômico dos movimentos (dos gestos).

Sem demorar em frases que, um século depois, já se tornaram lugar-comum como "a emoção é inimiga do riso", ou "não há cômico fora do humano", vejamos como se atualiza, quanto ao riso, o pensamento de Bergson.

Em primeiro lugar - diz o fílósofo -, o riso se dirige à inteligência pura, em contato com outras inteligências. O riso precisa de um eco, mas seu meio preferido é o da indiferença (nada de emoções envolvidas). Ri-se do que ocorre involuntariamente, do que tem a rigidez do mecânico, do que tem a estilização dos vícios, que nos simplificam. O cômico é inconsciente . Quando não há tensão e elasticidade o espírito sofre e o homem se limita ao automatismo fácil do hábito e é presa de certa rigidez, em seu comportamento. A rigidez suscita o cômico e o riso é seu castigo. Uma fisionomia é cômica quando pertence a um indivíduo que tem nela toda sua vida moral cristalizada, como uma careta fixa, única e definitiva.

Quanto às formas e aos gestos, faz-nos rir tudo o que tem a direção do mecânico. Dois rostos idênticos juntos, qualquer rigidez aplicada à vida viva (um vestido ridículo, a idéia de que uma cor possa servir como disfarce, contrariando a lógica da razão, o automatismo de uma marionete), o sentido brusco da superposição (chamar a atenção do físico quando é o moral que está em causa, o acoplamento de dois fenômenos opostos). "O gesto congelado (saisi) parece mais francamente maquinal quando se pode ligá-lo a uma operação simples, como se ele fosse entendido como mecânico. Sugerir esta interpretação mecânica deve ser um dos procedimentos favoritos da paródia" (Bergson, 1959a, 403). Para melhor entender o mecanismo da paródia, o crítico russo Iuri Tinianov sugere analisá-la junto com a estilização:

Tanto a estilização quanto a paródia vivem uma dupla vida: atrás do plano da obra há um outro plano, o plano que vai ser estilizado ou parodiado. Só que na paródia é necessária a defasagem dos dois planos, o deslocamento de um em relação ao outro; a paródia da tragédia será a comédia, (tanto por sublinhar seu aspecto trágico, quanto por substituí-lo pelo cômico), enquanto que paródia da comédia poderá ser a tragédia. Na estilização, ao contrário, ocorre a correspondência exata dos dois planos: do plano estilizante e do plano estilizado que se entrevê nele. Quando a estilização é motivada comicamente ou sublinhada, ela se transforma em paródia. [...] A substância da paródia consiste na mecanização de um simples procedimento, mecanização esta que só pode ser percebida, obviamente, apenas se se conhece o procedimento que vai ser mecanizado. Sendo assim, a paródia desempenha um papel duplo: 1) mecaniza um determinado procedimento; 2) organiza um novo material que é justamente o velho procedimento mecanizado. A mecanização do procedimento pode ocorrer graças a sua repetição, que não coincide com o plano da composição, ou com a inversão das partes (exemplo, a leitura de um poema do fim para o começo), ou ainda com o deslocamento do significado mediante um jogo de palavras (as paródias escolares de poemas clássicos, obtidas pelo uso de refrōes com duplo sentido), enfim, veiculando o significado por meio de procedimentos que o contradizem. (Tynjanov, 1968, 139, 150.)

O segundo artigo de Bergson diz respeito ao cômico das situações e das palavras. 
A fantasia cômica - diz Bergson - obedece às mesmas leis das harmônicas do som fundamental: quando um musicista produz o som de uma nota musical em seu instrumento, outras notas surgem por si sós, menos sonoras que a primeira, ligadas a ela por certas relações definidas, que lhe imprimem seu timbre e a ela se acrescentam. No caso do cômico, digamos que numa circunstância qualquer alguém seja ridicularizado por seu jeito "profissional"; pois bem, ele será potenciado por algum ridículo físico. Quando Molière - exemplifica Bergson - nos apresenta os dois médicos histriões de $O$ Amor Médico, um deles fala lentamente, espaçando o seu discurso, e o outro gagueja. Habitualmente está no ritmo ou em alguma idiossincrasia da fala a singularidade física destinada a completar o ridículo profissional.

Outra situação cômica por excelência é a da repetição, enquanto sentimento comprimido que se estende, ou, ao contrário, como idéia que se diverte a comprimir de novo o sentimento. Uma variante desta pode ser a personificação de dois partidos contrários, reunidos numa combinação mecânica, geralmente reversível: o efeito produzido é o de uma oscilação, de um desdobramento, de uma circularidade. $O$ Vaudeville gravita em volta dessa idéia. Também as idéias de desproporção, distração existencial ou imperfeição individual ou coletiva que exigem um "concerto" imediato, que normalmente não dá em nada, costumam provocar o riso. Neste caso vale a definição que dele dá Spencer, um dos grandes mestres de Bergson, citado por este : "O riso é o esforço que de repente encontra o vácuo" (Bergson, 1959a, 427).

Além da repetição, o procedimento da inversão é um dos fundamentos do cômico de situação. Suas variantes e desdobramentos já foram estudados sobejamente por Bakhtin e sua escola, não havendo em Bergson nada que lá não tenha sido revisto.

A terceira e última instância do cômico de situação seria, para Bergson, a assim chamada interferência de séries : uma ação é sempre cômica quando pertence, ao mesmo tempo, a duas séries diferentes de acontecimento absolutamente independentes e pode ser interpretada como a superposição de dois sentidos diferentes ao mesmo tempo. É o caso do trocadilho, do qüiproquó, de uma pequena comédia dentro de uma outra, grande. O efeito é sempre o de certa mecanização da vida.

Quanto ao cômico das palavras, uma distinção deve ser feita, logo no início, entre o cômico que a língua imprime e o que a língua cria. Obviamente, o segundo é intraduzível. Enquanto o cômico é sempre risível, isso não ocorre com o esprit.

O mot d'esprit (modalidade do esprit, tomado no sentido estreito), pode ser obtido como que recorrendo a uma fórmula farmacêutica (adensar o mot d'esprit numa espécie de cena a ser visualizada; procurar a categoria cômica à qual pertence a cena; reduzir a expressão a seus termos mais simples. Exemplo: "Sinto dor no seu peito"), sendo que a frase que o contém terá sido submetida, para tornar-se cômica, a um dos três procedimentos citados anteriormente para o cômico das situações: repetição, inversão, interferência de séries. (No caso da palavra, o procedimento da repetição funcionará, por exemplo, criando uma sensação de rigidez, até que o falante se "enrole" numa dobra de sua fala, e acabe dizendo o que não queria dizer. O caso da inversão, implicaria, por exemplo, uma transposição cômica das proposições, como na frase, "Por que você põe o terraço sob o meu cachimbo?" e, no caso da interferência de séries, será possível obter-se um efeito cômico, por exemplo, transpondo a expressão natural de uma idéia, num outro tom [do solene ao familiar, do coloquial ao técnico etc.].) 
O esprit tomado no sentido amplo, ao contrário, revela uma maneira dramática de pensar, faz os pensamentos dialogar entre si como pessoas. Seu portador, o homem de espírito, tem algo de poeta. Como a criação poética exige certo esquecimento de si, o homem de espírito deve perder como que o domínio sobre suas idéias e deixar que elas conversem entre si, deve ver as coisas sub specie theatri.

Pertencem ao esprit tomado no sentido lato duas figuras muito importantes: o humour e a ironia.

Ambas as figuras, segundo Bergson, pertencem ao gênero da sátira, sendo porém, em alguns sentidos, uma o contrário da outra. No humour, descreve-se meticulosamente o mal que é, fingindo-se crer que é justamente assim que as coisas deveriam ser. Na ironia, descreve-se o que deveria ser, fingindo-se acreditar que é exatamente o que é. Acentua-se a ironia elevando-se, gradativamente, a idéia do bem que deveria ser. Acentua-se o humour, ao contrário, rebaixando-se o mal que é, para nele notar suas particularidades negativas, com fria indiferença. Ao humour agradam os termos técnicos, os fatos precisos; à ironia, os elementos de natureza oratória.

Cabem aqui, agora, duas intervenções: a de Pirandello, quanto ao humorismo, e a de Paul de Man, quanto à ironia.

O se [diz Pirandello numa de suas muitas caracterizações do humorismo], esta partícula que pode se inserir feito cunha em qualquer acontecimento para desagregá-lo, é o grande instrumento do humorismo, que consiste no sentimento do contrário, provocado pela particular atividade da reflexão, que é o contrário do sentimento, embora o acompanhe passo a passo, como a sombra acompanha o corpo (Pirandello, 1996, 15).

[...] o esprit [diz Bergson] consiste, muitas vezes, em se prolongar a idéia de um interlocutor até o ponto em que este passa a exprimir o contrário de seu pensamento [...] Ele é pego, por assim dizer, na armadilha de seu próprio discurso. Acrescentemos, agora, que esta armadilha é também, freqüentemente, uma metáfora ou uma comparação cuja materialidade se volta contra ele (Bergson, 1959a, 442).

Observamos aqui que aquilo que Pirandello.chama de humorismo corresponde ao que Bergson chama de esprit tomado, como ele quer, em sentido lato, enquanto que aquilo que Bergson chama de humour (utilizando o termo inglês) não passa de uma das modalidades do esprit.

Mais delicada é a questão da ironia. Em seu ensaio sobre $A$ Retórica da Temporalidade, Paul de Man retoma a figura, como Bergson, a partir de Aristóteles: "dizer algo, para querer dizer outra coisa", mas vai mais além, mesmo após ter apontado a diferença específica da ironia, em relação aos outros tropos, uma vez que a lei geral de Aristóteles pode-se aplicar a todos eles. Para tanto, de Man vai buscar numa obra esquecida de Charles Baudelaire, De l'Essence du Rire a citação:

[...] pour qu'il y ait comique [...] il faut qu'il y ait deux êtres en présence; - que c'est spécialement dans le rieur, dans le spectateur, que gît le comique;- que cependant, relativement à cette loi d'ignorance, il faut faire une exception pour les hommes qui ont fait métier de developper en eux le sentiment du comique et de le tirer d'eux-mêmes pour le divertissement de leur semblables, lequel phénomène rentre dans la classe de tous les phénomènes artistiques qui dénotent dans 
l'être humain l'existence d'une dualité permanente, la puissance d'être à la fois soi et un autre" (Baudelaire, 1962, 215)

Pois bem, diz Paul de Man, a natureza desta duplicação é essencial para a compreensão da ironia.Trata-se, na verdade, de uma relação interna à consciência, entre dois self, mas não intersubjetiva. Le comique absolu, ou a ironia, para Baudelaire, consiste numa relação entre o homem e aquilo que ele chama de natureza, onde o dédoublement designa, assim, a atividade de uma consciência pela qual o homem se diferencia do mundo não humano.Essa disjunção não ocorre apenas por meio da linguagem, enquanto categoria privilegiada,mas transfere o self do mundo empírico para o mundo constituído de e na linguagem - linguagem essa que ele encontra no mundo como uma entidade entre outras, mas que permanece única por ser apenas ela que pode diferenciá-lo do mundo. A linguagem, assim concebida, divide o sujeito em um self empírico, imerso no mundo, e um self que se torna como que um signo, ao tentar diferenciar-se a autodefinir-se.

$\mathrm{Na}$ descrição de Baudelaire, importa verificar que a divisão do sujeito em consciência múltipla se dá em correlação à idéia de queda. $O$ fato de "cair"introduz no processo o ingrediente da ironia. No momento em que o indivíduo determinado pela linguagem ri de si mesmo, ao cair, ele está rindo da mistificação que ele fazia de si próprio. A queda, tanto no sentido literal quanto no teológico, recorda-lhe o caráter reificado, instrumental, de sua relação com a natureza, na medida em que esta pode, a qualquer momento, tratá-lo como uma coisa e ele,ao contrário, não tem o poder de transformar a ínfima parte dela em algo humano. Neste sentido a queda pode significar uma maior sabedoria, sabedoria esta obtida, porém, às custas de sua própria queda e não de outrem. Pois bem, o ser dúplice e irônico que o homem constitui por meio de sua linguagem parece poder vir a existir somente às custas de seu self empírico, caindo (ou surgindo) do estágio de acomodação mistificada, para o do conhecimento dessa mistificação. A linguagem irônica, portanto, divide o sujeito em duas partes: uma, empírica, que vive em estado de inautenticidade e outra, que existe apenas enquanto linguagem, que assevera o conhecimento dessa inautenticidade. (Isso não significa, porém, que se trate de uma linguagem autêntica; conhecer a inautenticidade não significa ser autêntico.) Na verdade, por baixo do questionamento da autenticidade do nosso sentido de "estar no mundo" move-se um processo que não é nada indolor, que vai ganhando velocidade e que só termina quando a ironia tiver completado seu curso. Desde uma pequena exposição, aparentemente inócua, de um autofingimento, até o absoluto, de uma simples litote, até a "vertigem da hipérbole". E, como diz Baudelaire,

Qu'est-ce que ce vertige? C'est le comique absolu; il s'est emparé de chaque être. Ils font des gestes extraordinaires, qui démontrent clairement qu'ils se sentent introduits de force dans une existence nouvelle... et ils s'élancent à travers l'oeuvre fantastique qui, a proprement parler, ne commence que lá, c'est "a dire sur la frontière du merveilleux" (Baudelaire, 1962, 259-260).

Ora, a "normalidade"só existe porque nós desejamos funcionar dentro das convenções de duplicidade e dissimulação, da mesma forma que a linguagem social dissimula a violência inerente às verdadeiras relações entre os seres humanos. Uma vez 
que a máscara é mostrada como máscara, o ser autêntico que está embaixo dela só pode beirar a loucura. Quando nós dizemos que a ironia se origina às custas do selfempírico, nossa fala deve ser tomada suficientemente a sério para ser levada ao limite: a ironia absoluta é a consciência da alienação, que por sua vez é o fim de qualquer consciência; é a consciência da não consciência, uma reflexão sobre a alienação de dentro da própria alienação. Pois essa reflexão só é tornada possível pela dupla estrutura da linguagem irônica: o ironista inventa uma forma de si que é "louca" mas que não sabe de sua loucura; em seguida, ele passa a refletir sobre a sua loucura assim objetivada. Isso poderia querer dizer que a ironia, enquantofolie lucide (de Man, 1971, 216), que permite à linguagem triunfar, mesmo nos casos extremos de auto-alienação, pode ser uma espécie de terapia, uma cura da loucura por meio da palavra.

Só que o ironista, que assim conquistou essa espécie de liberdade, não pode esperar que ela o leve a uma reconciliação tipo "final feliz"entre mundo e espírito.

Quase concomitantemente à primeira duplicação do self, graças à qual um sujeito puramente "lingüístico" substitui o self original, uma nova disjunção deve ocorrer. $O$ sujeito irônico fica tentado a construir a função da ironia no sentido de ajudar o self original, ligado ao mundo, e atuar como se ela existisse para o bem dele.

Ao contrário, o sujeito irônico deve ironizar de uma vez sua própria situação e encarar com distanciamento e desinteresse a tentação na qual está prestes a cair. Com isso ele reafirma a natureza puramente ficcional de seu universo e conserva a diferença radical que separa a fiç̧ão do mundo da realidade empírica.

A dialética da autodestruição e da auto-invenção que, para Baudelaire, caracteriza a mente irônica, é um processo infindo que não conhece síntese. Em termos temporais, significa que a ironia engendra uma seqüência temporal sem fim de atos de consciência. [...] A ironia divide o fluxo da experiência temporal em um passado que é pura mistificação e em um futuro que permanece para sempre ameaçado de uma recaída no inautêntico. Ele pode conhecer esta inautenticidade, mas não pode superá-la. [...] Tanto a alegoria, quanto a ironia, estão ligadas na sua desmistificação conjunta de um mundo orgânico postulado num modo simbólico de correspondências analogicas, ou num mundo de representações mimético, em que mundo e ficção poderiam coincidir. A ironia, em quase todas as citaçōes de Baudelaire, aparece como um processo instantâneo que se dá num único momento, "a ironia é instantânea como uma 'explosão' e a queda é repentina". (de Man, 1971, 220-222)

Os últimos e mais irônicos trabalhos de Baudelaire, os Tableaux parisiens - segundo de Man -, vão ficando cada vez mais curtos e o clímax está sempre no breve momento de uma pointe final. Este é o momento em que os dois self, o empírico e o irônico, estão presentes ao mesmo tempo, justapostos dentro do mesmo instante, mas como dois entes irreconciliáveis e disjuntos. A ironia é uma estrutura sincrônica, enquanto a alegoria apresenta-se como sucessão capaz de gerar a duração e a ilusão de uma continuidade que se sabe ilusória. Assim mesmo, as duas figuras, por mais distintas que sejam em caráter e estrutura, são as duas faces de uma mesma e fundamental experiência de tempo. $O$ jogo dialético entre as duas modalidades, bem como sua atuação recíproca com formas mistificadas de linguagem (tais como a representação mimética ou simbólica), que não consegue erradicar, constitui - segundo o crítico - o que se chama de história literária. 
"Movemo-nos em um campo de signos"- diz-nos agora Bergson, no final do Le Rire, chegando muito próximo ao pensamento de Nietzsche via Paul de Man²-, "vivemos numa zona intermédia entre as coisas e nós" (Bergson, 1959, 461). Viver consiste em agir - explica o filósofo - nós temos que apreender as relações úteis e esquecer as outras (o contorno das coisas, a cor, a forma). Isso seria factível se a realidade chegasse diretamente aos nossos sentidos e à nossa consciência; nossa alma vibraria em uníssono com a natureza e, nesse caso, não haveria utilidade nas obras de arte. Mas não é assim. Nós não vemos as coisas como elas são. Limitamo-nos, na maioria das vezes, em ler as etiquetas que estão coladas nelas. Esta tendência, nascida da necessidade (da "utilidade"), acentuou-se ainda mais sob a influência da linguagem. As palavras, que só notam das coisas sua função mais comum e seu aspecto banal, se insinuam entre elas e nós, mascarando a forma delas, se é que esta forma já não havia sido dissimulada por trás das necessidades que haviam dado origem à própria palavra. $E$ isso não se refere apenas aos objetos externos: ocorre o mesmo com nossos próprios estados de espírito, que não nos desvelam o que têm de íntimo, de pessoal, de original.

Pois bem, só o artista não adere à práxis da ação, da "utilidade" A arte tem como finalidade afastar os símbolos praticamente úteis, as generalidades convencionalmente aceitas, tudo o que mascara a realidade e nos colocar frente à frente... com a realidade. Esta pureza de percepção implica uma ruptura com a convenção útil, um desprendimento, enfim, uma certa imaterialidade de vida à qual se deu o nome de idealismo. É só pela força da idealidade que retomamos o contato com a realidade. A arte dramática não faz exceção a esta lei.

É no terceiro artigo, dedicado ao cômico do caráter, que Bergson exemplifica o poder de convicção e de conversão da arte, bem como a individualização de seu objeto e a universalização de seu efeito. Enquanto na tragédia o que interessa é o divisar estados de espírito, conflitos internos, e o refazer de uma ou várias vidas (não, porém, sua recomposição: a vida não se recompõe), através da visão de um poeta, na comédia trata-se de uma observação externa. O que interessa é ver o invólucro das pessoas: para rir devemos localizar o motivo na região média da alma e exercer um trabalho semelhante ao do médico: observação externa e resultado generalizável.

Para a comédia, o meio mais apropriado é o da vida social, sendo o ridículo de uma pessoa algo que não se assimila a ela, mas vive sobre ela como um parasita.

A disposição do caráter, na comédia, é profunda, para ser durável; superficial, para ficar no tom da comédia; invisível para quem a possui (o cômico é inconsciente); visível para os outros; corrigível imediatamente. A lógica da personagem cômica implica sempre contradição, é de um absurdo visível e determinado, que deriva do cômico mas não o cria, é efeito dele. Representa uma inversão especial do bom senso, algo como ver o que se pensa em lugar de pensar-se o que se vê. $O$ curioso é que para Bergson o absurdo cômico é da mesma natureza do absurdo do sonho: o espírito, apaixonado por si próprio, só procura, no mundo exterior, um pretexto para materializar suas fantasias. Os sentidos não estão completamente vedados, mas o sonhante, em vez de recorrer a

2. Leia-se, a esse respeito, o ensaio de Paul de Man sobre Nietzsche "Retórica de Tropos", em seu livro Alegorias da Leitura, op. cit. 
todas as suas memórias para interpretar o que os sentidos percebem, serve-se do que percebe para dar corpo à lembrança preferida. Na comédia, o mecanismo seria este: partindo-se de uma dada forma do risível, outras formas, que não contêm o mesmo fundo da primeira, tornam-se também risíveis por sua semelhança exterior com a primeira. Na comédia também há, como no sonho, um relaxamento das leis da lógica, que nos descansa da fadiga de pensar, a partir do momento em que nos associamos ao protagonista, simpatizando com ele. E também há, como no sonho, obsessões cômicas que vão crescendo até o absurdo final, e um tipo de demência muito característico: a fusão de duas pessoas, uma das quais é o dormente (ou, mutatis mutandis, o ator da comédia), ou ele se desprenderá de si próprio e ouvirá falar de si. Finalmente, quando a personagem cômica segue sua idéia automaticamente, é como se o fizesse em sonho. $O$ riso cômico é uma correção feita para humilhar o outro (que é uma marionete, para nós), contando com a malícia ou a maldade que há no fundo de cada homem ; nada deve ser procurado nele de justo ou de bom.

O riso [para terminar com uma imagem de Bergson] é, ele também (como a do mar), uma espuma à base de sal. Como a espuma, é frisante. É a alegria. $O$ filósofo que a recolher para saboreá-la encontrará nela às vezes, para uma pequena quantidade de matéria, uma certa dose de amargor (Bergson, 1959, 483).

\section{Bibliografia}

Aristóteles. Poética. In Os Pensadores IV (Tradução, comentários e índices analítico e onomástico de Eudoro de Souza). São Paulo, Victor Civita (Abril), 1973, pp. 443-553.

BeAudelaire, Charles. "De l'Essence du Rire". In Curiosités esthétiques: l'Art romantique et autres Oeuvres critiques. Paris, Garnier, 1962.

BenEdict, Ruth. O Crisântemo e a Espada. São Paulo, Perspectiva, 1972.

Bergson, Henri. "Le Rire". In Bergson, Henri. Oeuvres. Paris, Presses Universitaires de France, 1959, pp. 383-483.

"Matière et Mémoire". In Bergson, Henri. Oeuvres. Paris, Presses Universitaires de France, 1959. pp. 161-378.

Bernardini, Aurora Fornoni. Henrique IV e Pirandello. São Paulo, Edusp, 1990.

DE MAN, Paul. "The Rhetoric of Temporality". In Blindness and Insight: Essays in the Rhetoric of contemporary Criticism. New York, Oxford University Press, 1971, pp. 187-228.

"Retórica de Tropos" In De Man, Paul. Alegorias da Leitura. Rio de Janeiro, Imago, 1996, pp. 125-141.

Pirandello, Luigi. O Humorismo. São Paulo, Experimento, 1996.

Tynuanov, Jurij. "Dostoevski e Gogol (Per una Teoria della Parodia)" In Tynjanov, Jurij. Avanguardia e Tradizione. Bari, Dedalo libri, 1968, pp. 135-171.

Aurora Fornoni Bernardini

Professora Titular aposentada do Curso de Russo da USP e Professora de Pós-Graduação junto à Área de Teoria Literária e Literatura Comparada da USP. Rua Santos Dumont, 494 - 04638-000 - São Paulo - SP - Brasil 